\title{
Study on Opportunities and Challenges of College Ideological and Political Work under the Era of Cloud Computing
}

\author{
Linwang Zhou ${ }^{1, \text { a }}$ \\ ${ }^{1}$ Jiangxi Science \&Technology Normal University, Nanchang, Jiangxi, 330013 \\ ${ }^{a}$ email
}

Keywords: Ideological and Political Work, Colleges and Universities, Cloud Computing

\begin{abstract}
As the technology matures and continuous improvement, "cloud computing" in the ideological and political work has brought new challenges. Currently in initial use of "cloud computing," but also the main thing is to stay at the level of research and teaching, has not yet entered people's lives. Whether in science and technology literacy, the ability to monitor all aspects of training and career college students network are some drawbacks, it is difficult to adapt to "cloud computing" this new era. To this end, we need to go upstream, against the culture of science and technology talent, quantitative analysis, and interactive platform between teachers and other issues around the wound to seize the "cloud computing" has brought us opportunities, ideological and political Universities work referred to a new height.
\end{abstract}

\section{Introduction}

"Cloud computing" is based on the increase in Internet-related services, use and delivery models, usually involving to provide dynamic and easy scalable and often virtualized resources via the Internet. By remote data, tens of thousands of computers and computer servers are connected together to share data, whenever and wherever there is a network capable of data can be transferred out of the super service. "Cloud computing" is a network of science and technology from quantitative to qualitative leap, have broad application prospects. It appears both opportunities to ideological and political work as well as challenges.

\section{The "Cloud Computing" Concept}

"Cloud computing" is a large-scale data sharing, through virtual technology as the core, the scale-oriented economy, the Internet as the carrier, in accordance with the requirements of customers in a dynamic form of virtualization, the data model can be heavy volume shrinkage. In today's society, "cloud computing" is widely used not only said to be a form of technology, but a new service model. Through the "cloud computing" this mode, you can put different kinds of information data dynamic performance according to customer requirements in the form of out, user can build, operate and maintain the data. "Cloud computing" is mainly the central idea is the "cloud", "cloud" is the size of the form can be dynamically expanded by using the "cloud" services such as sharing resources like, very convenient to use as you do with water, electricity, gas as a low cost. Single "cloud" pay to use now available to the public in the form of time, we were known as the "public cloud."

\section{The "Cloud Computing" Characteristics and Functional Analysis}

"Cloud computing" features are reflected in three aspects: first, large-scale. "Cloud" by definition a considerable scale, to provide users an unprecedented computing power. Second, the low prices. "Cloud computing" unique forms of technology can be used to form a very low node. Centralized management of customer data can greatly reduce the high administrative costs. Third, easy to use and efficient. "Cloud" is a great resource, users demand the actual situation, the payment demand. And "cloud computing" does not exist in the diversity of specific requirements, through the "cloud" support any application can use. 
"Cloud computing" There are two main functional performance data processing and storage. "Cloud computing" can put large-scale centralized or distributed data processing. At the same time, "cloud computing" technology when managing data storage, data security and capable of real-time synchronization of effective technical support. 360 developed the "360 cloud disk" is a good "storage cloud" software. Users through the registration as a registered user, all sorts of things their documents, photos, and other software can be uploaded to the "cloud space", no longer need the traditional U disk. "360 cloud disk" In addition to providing upload and download files, you can also synchronize backup and restore backup. Then download to achieve through different devices or mobile devices.

\section{The Challenges in College Political Work}

In the early use of "cloud computing," but also the main thing is to stay at the level of research and teaching, has not yet entered people's lives. As the technology matures and continuous improvement, "cloud computing" in the ideological and political work has brought new challenges. Mainly manifested in several ways:

Ideological and political work is a study of scientific disciplines ideology. With the front line of technology, people are constantly expanding to new things and new knowledge, capacity, requires ideological and political work have advanced, real-time work methods, and technology to achieve convergence. Update increasingly technological development, university students stage application capabilities of high-tech getting stronger. Literary institutions, but also has a large number of Internet experts. Ability of students to science and technology has been upgraded so that counselors should advance with the times, in the computer information age "cloud computing" era is very important. Current Political Conservation Science and Technology team is not high. Be able to understand and familiarize themselves with very few high-tech network of teachers in the ideological and political NETs. First, the source of ideological and political teacher needs to be improved. Present among the various colleges and universities, ideological and political teacher are concentrated graduated from the school, they are derived from the professional ideology education students. Investigation for the relative lack of technological literacy. Secondly, the ideological and political teacher vocational training needs to be improved. Currently, the training focuses on current political affairs in communication skills to cultivate scientific and technological knowledge and skills are more often ignored. Then, the ideological and political education philosophy of science and technology do not pay attention. The lack of progress of the times and technological means to reduce the work efficiency. Or in the eighties and nineties level talk on which way to visit.

Ideological and political education through computers and the Internet and other means, to the unity of qualitative and quantitative analysis at this stage. Any one thing all have quality and quantity of qualitative, or both the quality and quantity of the organism. The same is true of ideological and political education, both qualitative measure, but also the amount of the standard. Often can not achieve balance in qualitative and quantitative real educational work. It focuses on the qualitative and quantitative ignored. One reason is the traditional ideas of cause, they tend to believe that the main ideological and political work in contact with people, emphasis on qualitative; the other one can not be a reason for a quantitative analysis by the technical conditions of the original analysis. In the "cloud computing" coming

\section{The "Cloud Computing" Opportunities}

In the "cloud computing" era, as we imagine, in the ideological and political work is difficult to "cloud computing" concept introduced to the specific work to which, in the minds of college students were likely to be unable to recall both the intersection of . So, although there are many challenges, we should go upstream, should seize the "cloud computing" era of opportunity, improve the level of ideological and political work to a new level. Specifically should be a breakthrough in the following areas:

As we have just talked about, the existing ideological and political ranks of poor conservation 
science and technology. Problems on both ideas, but also institutional issues. First, the ideological and political philosophy should be transformed to enhance the status of science and technology factors into the main position, thought to pay attention to it, relying on the basis of two aspects never work towards the effective breakthrough: First, the ideological and political team breakthrough recruitment system. Relying on the existing professional set each university distinctive characteristics appropriate to introduce students with a background in science and engineering, especially computer science background to add to the ideological and political ranks. Politics teachers to make "cloud computing" technology has the ability to enhance the rate of. Secondly, the ideological education team of professional reform. High-tech knowledge training has increased, when necessary, through the outer please some background knowledge of the person or company to strengthen training. Political science and technology team improved conservation shortage.

Community caucus branch can be based on "cloud computing" to build a virtual network environment for political education. Through the popularity of the network to improve the structure of the virtual online learning distance education has become a hot spot. Through the "cloud computing" will set learning materials and related applications in the "cloud" side, the learner only through the "cloud" side will be able to download and access to information required by the application, the process of using it is convenient and efficient.

In reality the course of teaching, ideological and political teacher through the "cloud computing" to understand and use, and students can make themselves better and more effective communication, promote the improvement of the teacher's academic level. Teachers and students through interactive learning, so that students and teachers of technical and political quality can be improved simultaneously. A favorable double-edged sword. "Cloud computing" provides a wealth of educational resources, but also provides an equal, open communication platform that enables teachers and students to interact and grow together on the platform. In teaching, closer teacher-student relationship, barrier-free communication between teachers and students. Therefore, we not only want to strengthen the traditional teaching, but also through the Internet "cloud computing" to improve and enhance our teaching. Only in this way can the ideological and political education workers do not fall behind the times.

\section{Conclusion}

"Cloud computing" represents the future direction of network technology, reflecting the advanced productive forces, the impact on human life. "Cloud computing" era, the ideological and political work opportunities and challenges. The core of education is to educate people. It turns out that in the new situation of ideological and political workers should continue to explore new ways to master the "cloud computing" technology, the courage to face the challenges and seize the opportunity to develop the level of ideological and political work to a new level.

\section{References}

[1] Tan Meiqin. On The Challenges and Opportunities for the Cyl Organizations at Mikoto Network Times Ideological and Political Work Faces [J]. Value Engineering, 2011, V.30; No.22602: 237.

[2] Chen Chunfan. Opportunities, Challenges and Countermeasures Chen Chunfan of Ideological and Political Work [J]. Intelligence, 2011, 11: 283-284.

[3] Yao Xin. University Ideological and Political Work In The New Media Age [J]. Education Article (on Xunkan), 2014, No. 28909:10-11. 